Acta Hispanica (2014) 19: 27-37

\title{
LA IGLESIA CATÓLICA CUBANA Y EL ESTADO EN 1959 SEGÚN LA CIRCULAR VIDA NUEVA
}

\author{
EMŐKE HORVÁTH
}

\author{
Universidad de Miskolc
}

Resumen: El estudio analiza las relaciones entre la iglesia católica cubana y el estado inmediatamente después de la victoria de la revolución cubana en 1959. La lucha de Fidel Castro y del Ejército Rebelde fue apoyado por sacerdotes y fieles católicos también. A principios de enero una carta pastoral, con el título Vida Nueva, fue emitida por Mons. Enrique Pérez Serantes, el primado de Cuba. Esta carta es una fuente principal para investigar la interpretación de la nueva situación política por parte de la iglesia. A través del analisis de la carta pastoral podemos entender la actitud de la iglesia y de los fieles hacia la revolución, y su líder, Fidel Castro. Poco después de la victoria de la revolución, a pesar de las promisas iniciales, el estado se opuso a la iglesia. Había comenzado el debilitamiento de las instituciones eclesiales y en otras áreas la eliminación de ellas.

Palabras clave: iglesia católica cubana, Enrique Pérez Serantes, primado cubano, revolución cubana, Vida Nueva

\begin{abstract}
The paper analyzes the relationship between the Cuban government and the Catholic Church after the victory of the Cuban Revolution in 1959. The struggle of Fidel Castro and his fellow rebels against the Batista dictatorship was supported by a significant number of priests and catholic faithfuls. Three days after the victory of the Ejercito Rebelde, a pastoral letter with the title of Vida Nueva (New Life) was issued by Mons. Enrique Pérez Serantes, the primate of Cuba. This letter is a main source for the interpretation of the Church and State relations at the beginning of the political changes. The analysis of the letter helps to understand the attitude of the Catholic Church toward the new political system and it's leader, Fidel Castro. After the victory of the revolution, despite the earlier promises, the new Cuban State vigorously opposed the Catholic Church. The new goverment began to weaken its institutional system, and aspired to the elimination of these institutions in some fields.
\end{abstract}

Key words: Cuban Catholic Church, Enrique Pérez Serantes, Cuban revolution, Vida Nueva, Church and State relations 
El primero de enero de 1959 Fidel Castro y sus compañeros de lucha entraron a la Plaza Principal de Santiago de Cuba, al Parque Céspedes, y dos días después, el arzobispo de la ciudad, el primado de Cuba, Enrique Pérez Serantes publicó su carta pastoral titulada Vida Nueva con el objeto de ser leído en todas las iglesias de la diócesis.

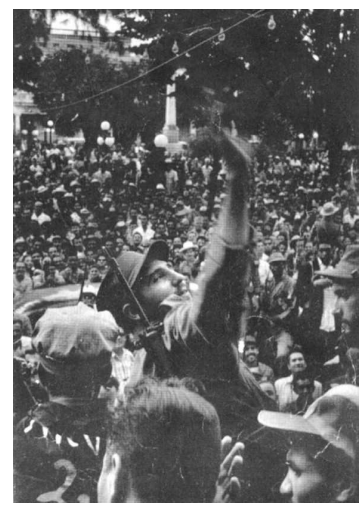

Fidel Castro y el Ejército Rebelde en la Plaza Principal de Santiago de Cuba, enero de 1959 http://www.cubadebate.cu/opinion/2014/01/01/fidel-castro-el-1-de-enero-de-1959-esta-vez-sique-es-la-revolucion/\#.U_4G_KPQ_IU, fecha de consulta: 7 de agosto de 2014

Este escrito puede ser considerado como una fuente de gran valor histórico, porque mediante su ayuda podemos obtener una perspectiva de qué opinión tenía -la posteriormente tan atacada- Iglesia Católica sobre los cambios en el momento de la victoria de la revolución; y cómo era considerado, por parte de la Iglesia, Fidel Castro, el dirigente de los que luchaban en contra de la dictadura Batista. Aunque la circular solamente tenía vigor en una sola diócesis, se la puede considerar como un tratado general, formador de opinión para la comunidad católica de todo el país, ya que surgió de la pluma del primado cubano, del líder de la jerarquía católica, por lo que para los demás obispos sirvió como una manifestación orientadora. Lo expresado por el arzobispo tampoco era desconocido para los habitantes no creyentes de Santiago de Cuba, porque quien estuvo presente en el Parque Céspedes, prácticamente pudo escuchar un discurso sobre el contenido de la circular, que dio como último orador del evento, Pérez Serantes, invitado por Castro. ${ }^{2}$

\footnotetext{
1 "Vida Nueva", in: La Voz de la Iglesia en Cuba: 100 Documentos Episcopales, Editado por la Conferencia de Obispos Católicos de Cuba. México, 1995, 22-25.

2 Augusto MONTENEGRO GONZÁLEZ, "Historia e historiografía de la Iglesia en Cuba (1959-1976)", in: AHIg 18, 2009, 261-293, 263.
} 


\section{La Iglesia Católica antes de la revolución}

En relación a la interpretación de la situación de la Iglesia Católica cubana previa a la revolución, se formularon varios puntos de vista por parte de los investigadores, pero las opiniones de los autores fueron bastante influidas por sus orientaciones políticas, por sus relaciones con la iglesia, y eventualmente por afectaciones personales. Los estudios relativos concuerdan en que la Iglesia Católica cubana de los años 50 dentro de los países latinoamericanos puede registrarse entre las iglesias débiles. Aunque en la consideración del nivel de debilidad se presentan diferencias. Margaret Crahan considera la debilidad más en el sistema institucional de la iglesia que en su integración a la cultura. ${ }^{3}$ John C. Super fue quien negó más firmemente las visiones que expresaban la debilidad de la Iglesia Católica cubana. Super no encontró que la iglesia cubana fuese ni más débil ni más conservadora que en general las iglesias católicas latinoamericanas de los años 50, pero no pudo ofrecer un análisis más profundo a parte de esta conclusión. ${ }^{4}$

Durante la dictadura Batista los dos estudios estadísticos realizados por la Agrupación Católica Universitaria, en 1954 y en 1957, principalmente entre la población rural sobre su catolicismo, resultaron ser una fuente sorprendente y revelaron bastante bien las diferencias visibles entre los grupos sociales urbanos y rurales. Según los datos de 1954, de todos los encuestados el 72,5\% declaró ser católico. ${ }^{5} \mathrm{Si}$ seguimos detallando más este porcentaje, podemos observar que la clase media y la burguesía declaraba en un $88 \%$ y en un 100\% respectivamente ser católica, y en cambio, las clases más bajas en su totalidad solo en un $74,5 \% .{ }^{6} \mathrm{El} 91 \%$ de los niños fue bautizado, pero ya sólo el $50 \%$ hizo la primera comunión. ${ }^{7}$ Un resultado igualmente inesperado ofreció tres años más tarde el estudio realizado entre los campesinos que formaban el $60 \%$ de la población. Aunque el 96,5\% de los encuestados afirmó creer en Dios, sólo el 52,1\% declaró ser católico y el 41,41\% consideraba no pertenecer a ninguna religión. El 88,84\% de los que se consideraban católicos nunca había asistido a una misa, solo el 4,25\% estuvo tres o más veces al año en un templo. El 53,51\% de los encuestados nunca había visto al

\footnotetext{
${ }^{3}$ Margaret E. CRAHAN, "Salvation through Christ or Marx: Religion in Revolutionary Cuba", in: Journal of Interamerican Studies and World Affairs, Vol. 21, No.1, Special Issue: The Church and Politics in Latin America, Feb. 1979, 156-184, 159.

${ }^{4}$ John C. SUPER, "Interpretations of Church and State jn Cuba, 1959-1961", in: The Catholic Historical Review, Vol. 89, Num. 3, July 2003, 511-529.

5 John M. KIRK, "La Iglesia en Cuba: ¿Emergiendo desde las catacumbas?", in: Nueva Antropología, Vol. IX, No. 31, México, 1986, 23-48, 25.

${ }^{6}$ Ramón TORREIRA CRESPO, "La iglesia católica en la primera oleada migratoria cubana" in: Colección Foro, La Habana, 2005.

7 Mateo JOVER MARIMÓN, "The Church", in: Revolutionary Change in Cuba, Ed. Carmelo MESA-LAGO, Pittsburgh, 1974, 400.
} 
La Iglesia Católica cubana y el Estado en 1959 según la circular Vida Nueva

párroco de su comunidad. ${ }^{8}$ Durante el análisis de los matrimonios según la encuesta, en el 16\% de los casos podemos hablar de bendiciones nupciales eclesiales, el 48,5\% en cambio mantiene una relación de convivencia en vez de matrimonial y el resto solo contrae un matrimonio civil.

Los datos revelan la insostenibilidad en el número de sacerdotes y dentro de esto su distribución estructural. El número de clérigos desde la época colonial resultó ser una cuestión neurálgica, no solo en el caso de Cuba, sino prácticamente en toda América Latina. La situación empeoró tras lograr la independencia, cuando una parte del clero abandonó el territorio y los nombramientos eclesiales fueron dificultados por España con la exigencia de mantener el ius patronatus; de esta manera, en muchos casos los cargos del alto clero permanecieron sin ser ocupados. Una parte de los seminarios fue cerrada con lo que la provisión de personal también quedó en peligro, por lo que la Santa Sede trató de reclutar sacerdotes del extranjero, principalmente de Europa, para labores misioneras a América Latina. ${ }^{9}$ En el caso del clero cubano también se puede presenciar que su conformación se inclina a favor de los europeos, su mayoría proveniente de España, tal como el primado mismo. ${ }^{10}$ En abril de 1958 en el Diario de la Marina, Pérez Santos habló también sobre la cuestión del número del personal del clero cubano. ${ }^{11}$ En su opinión el número reducido de curas en su diócesis llegó a niveles descendentes alarmantes, faltan tantos curas que la atención a los enfermos enfrenta severas dificultades también, los habitantes de la provincia tienen que vivir prácticamente sin poder participar en eventos religiosos. A pesar de que el arzobispo mismo hizo tanto para que esto no fuera así. En 1929 fundó un seminario menor en Camagüey, y ha sido el motor de su funcionamiento para poder atraer la mayor cantidad de jóvenes a la vocación sacerdotal, pero tampoco trajo un cambio radical esta iniciativa. Años más tarde, tuvo que ser cerrada esta institución a falta de candidatos dedicados. ${ }^{12}$ En 1955 solo 661 sacerdotes prestaron servicio en el país (de estos solamente 125 de origen cubano), 329 monjes y 1872 monjas (556 cubanas) formaron parte de la vida religiosa. ${ }^{13}$ O sea, había un cura para cada 8800 personas, esta proporción en cinco años empeoró a 9400 personas. ${ }^{14}$ Enrique Dussel comparó los datos de 1954 de tres grandes ciudades latinoamericanas, La Habana, São Paolo y

8 Margaret E. CRAHAN, “Cuba: Religion and Revolutionary Institutionalization”, in: Journal of Latin American Studies, Vol. 17, No. 2, Nov. 1985, 319-340, 321.

${ }^{9}$ Emőke HORVÁTH, “A Rio de Janeiro-i Püspöki Konferencia (1955) és a Latin-Amerikai Általános Zsinat (1899) párhuzamai a Szentszék Latin-Amerika politikájának tükrében”, in: Acta Scientiarum Socialium 36, Kaposvár, 2012, 45-52.

${ }^{10}$ Enrique Pérez Serantes (1883-1968) de la Galicia española, nació en la población llamada Tuy, realizó sus estudios básicos en la provincia de Orense, luego llegó a Cuba en 1901.

${ }^{11}$ Diario de la Marina, 28 de abril de 1958, 8A.

12 Mons. Ramón SUÁREZ POLCARI, "Los dos grandes Arzobispos de Santiago de Cuba", in: Palabra Nueva, 11-14, 13.

${ }^{13}$ John C. SUPER, op. cit., 513.

14 Jover MARIMÓN, op. cit., 402.

30 | Acta Hispanica 19: 27-37, 2014, ISSN: 1416-7263 
Buenos Aires, según el número de habitantes, de parroquias y el número de habitantes por parroquias. De los datos obtenidos, resulta que en el caso de La Habana correspondían casi tres veces más habitantes, 61.535 personas, a cada parroquia, en cambio, en Buenos Aires 28.900, en São Paolo 22.692 personas era lo normal, o sea, la falta de sacerdotes se hizo ampliamente más notoria en La Habana. ${ }^{15}$ Esta proporción es más notoria aún si consideramos el hecho de que durante todo el siglo XX el 85\% de todo el clero cubano se concentró en La Habana. ${ }^{16}$

Según los datos, podemos constatar que la iglesia católica parece menos integrada socialmente en Cuba, manifestando a su vez en forma plástica la diferencia que se presencia en las preferencias religiosas de los habitantes de las ciudades y de las provincias, ya que según las encuestas, podemos considerar que el credo católico pudo obtener suelo firme entre la población citadina, principalmente blanca, de las clases altas y medias. A pesar de todo esto, la sustancia de la cubanidad en tiempos anteriores a la revolución se fundió clara e irrevocablemente con la fe católica, principalmente con su práctica reflejada mediante la religiosidad popular. ${ }^{17} \mathrm{La}$ devoción y fiestas al culto de María, la Virgen de la Caridad del Cobre estuvieron imborrablemente presentes en la sociedad, en la actualidad el santuario de la Patrona del país sigue siendo centro importante de peregrinación en Cuba.

\section{El primado cubano}

El arzobispo de Santiago de Cuba, el primado cubano, Enrique Pérez Serantes llegó a La Habana extraordinariamente joven, sólo con dieciocho años, para evitar el reclutamiento al servicio militar obligatorio, lo que fue ampliado también a las personas pertenecientes al clero por el Partido Liberal, que llegó al poder en España en marzo de 1901. Terminó este año sus estudios en el Seminario Conciliar de Orense, pero por el decreto anteriormente mencionado no pudo continuar sus estudios en España, tuvo que emigrar. La elección de la familia por La Habana se debió a que Manolo Hierro, uno de los familiares de la madre de Pérez Serantes vivió en esta ciudad. ${ }^{18}$ En la capital cubana fue durante tres años miembro trabajador de aquella comunidad jesuita en la

\footnotetext{
${ }^{15}$ Enrique DUSSEL, A History of the Church in Latin America. Colonialism to Liberation (1492-1979). Grand Rapids, 1981, 119. En 1954 en La Habana para un millón de habitantes hubo 16 parroquias, así a cada parroquia le correspondían 61.535 fieles. Para 3.497.000 habitantes de Buenos Aires hubo 121 parroquias, así a cada parroquia le correspondían 28.900 fieles. En el caso de São Paolo los 3.100.000 habitantes tenían 115 parroquias, a cada parroquía le correspondían 22.692 fieles.

${ }^{16}$ Margaret E. CRAHAN, 1985, op. cit., 321.

${ }^{17}$ Margaret E. CRAHAN, "Civil Society and Religion in Cuba: Past, Present and Future", in: Changes in Cuban Society since the Nineties. Edited by Joseph S. Tulchin - Lilian Bobea - Mayra P. Espina Prieto - Rafael Hernández with Elizabeth Bryan, Woodrow Wilson Center Reports on the Americas 15, Washington, 2005, 231-242, 232.

${ }^{18}$ Ignacio URÍA, Iglesia y revolución en Cuba. Enrique Pérez Serantes (1883-1968), el obispo que salvó a Fidel Castro, Madrid, 2011, 29.
} 
La Iglesia Católica cubana y el Estado en 1959 según la circular Vida Nueva

que posteriormente Fidel Castro cursaría sus estudios, o sea, los dos se formaron en el mismo ambiente intelectual, a pesar de que con el bagaje intelectual aquí recibido hayan recorrido un camino muy distinto. En 1903 se decidió definitivamente por la carrera sacerdotal. De La Habana lo mandaron a Roma, donde llegó a residir en el Seminario dedicado a los llegados de América Latina, Colegio Pio Latino Americano. No pudo estudiar en Cuba, porque tras las luchas independistas el Seminario de La Habana, donde hubiera podido obtener su grado teológico, fue clausurado. ${ }^{19}$ El Colegio Pio, fundado por el Papa Pío IX en 1858, jugó un papel determinante en la formación de la élite eclesial de la iglesia latinoamericana y sus redes de contacto. Desde la creación de esta institución el alto clero de la región provendrá de aquí, siendo en parte justamente esta la intención de su creador, al lado de la formación en teología de alto nivel, crear una élite que sea capaz y que desee identificarse por completo con la Santa Sede. ${ }^{20}$

Enrique Pérez Serantes obtuvo su título de doctor en filosofía y teología en la Pontificia Universidad Gregoriana. Al finalizar sus estudios en 1910 regresó a La Habana donde desempeñó la labor de profesor en el Real Seminario Conciliar de San Carlos y San Ambrosio. Este mismo año se ordenó sacerdote. En 1922 lo nombraron obispo para la diócesis de Camagüey, en 1948 tras la muerte del Mons. Zubizarreta se trasladó a Santiago de Cuba y ocupó el puesto arzobispal, convirtiéndose así a su vez en el Primado de Cuba, ya que tradicionalmente le correspondía a este arzobispado este cargo. Ocupó este cargo hasta la fecha de su muerte en 1968. ${ }^{21}$

Enrique Pérez Serantes basándose en las doctrinas sociales de la iglesia (la encíclica Rerum Novarum de Leo XIII de 1891) mostró honda sensibilidad social, trató de brindar una mano auxiliadora para los obreros, para los desvalidos y para los pobres. Ya en sus años de La Habana publicó regularmente en el periódico El Faro ${ }^{22}$, llegó a atraer a su alrededor un pequeño grupo de trabajo. Durante su labor social en Camagüey fundó una clínica que brindó entre otras cosas en forma gratuita servicio médico y odontológico para los más necesitados, pero también se dedicó en lo intelectual a sus feligreses, les enseñó a leer y a escribir y recibieron la oportunidad de aprender contabilidad y costura. En su diócesis de Santa Cruz del Sur en 1932 pasó un ciclón arrasador. El obispo se apresuró con el primer convoy militar al lugar de los acontecimientos, una parte de los damnificados fueron alojados en el edificio del obispado, levantaron una cocina comunitaria en uno de los monasterios, prepararon trescientas porciones de comida al día con la financiación del obispado, la cocina funcionó durante dos años. En forma de reconocimiento por su labor, en 1933 recibió el título honorífico de Hijo Adoptivo de la Provincia de Camagüey, luego recibió lo mismo en 1950 de la Municipalidad de Santa Cruz del Sur. ${ }^{23}$ Según su biografía y sus

${ }^{19}$ Ignacio URÍA, op. cit., 32-33.

${ }^{20}$ Emőke HORVÁTH, op. cit., 48.

${ }^{21}$ Para los datos biográficos me basé en los escritos citados de Mons. Ramón Suárez Polcari.

22 El Faro arrancó el 22 de diciembre de 1879 bajo la dirección de Serafín Costales.

${ }^{23}$ Ignacio URÍA, op. cit., 65-66. 
memorias se despliega sobre él una visión de un prelado extraordinariamente activo, emprendedor, con gran capacidad de trabajo, que toma en consideración y vive la doctrina social de la iglesia, quien se dirige a los pobres, desvalidos, dedicado a no solo guardar con vida el catolicismo cubano, sino incrementar obstinadamente su número. Perteneció a los prelados que mantuvo una relación diaria y viva con sus feligreses, visitaba regularmente las zonas más abandonadas de su diócesis, hasta las granjas.

\section{Publicación de la Vida Nueva tras la victoria de la Revolución}

Enrique Pérez Serantes el 1 de enero de 1959 estuvo parado al lado de Fidel Castro, saludando a la multitud jubilosa y a la victoria de la revolución.

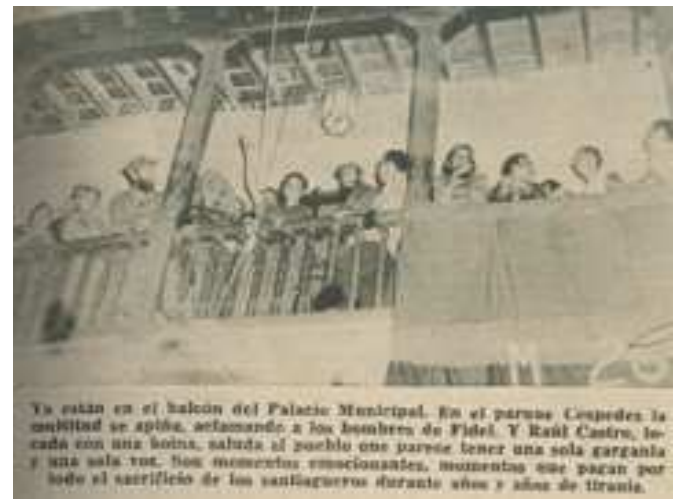

En el balcón del Palacio Municipal, Santiago de Cuba, 1 de enero de 1959

http://www.cubamilitar.org/wiki/Caravana_de_la_Libertad, fecha de consulta: 7 de agosto de 2014

Los dos se conocieron ya mucho antes. En la biografía escrita sobre Castro por Thomas M. Leonard se habla sobre el obispo como un amigo de la familia. ${ }^{24}$ Esta relación personal no, pero sí se respalda la estrecha relación del padre de familia y el obispo en las memorias de Juanita Castro - hermana de Fidel Castro - según las cuales su padre conocía a Pérez Serantes, quien estuvo varias veces en Birán ${ }^{25}$, si tenía que realizar algún trabajo misionero en la zona. También menciona en el reportaje que su padre apoyaba financieramente las actividades edificadoras de la Iglesia del obispo. ${ }^{26}$ Esta buena relación, pienso que también se debió a sus orígenes, ya que ambos, Ángel Castro y Pérez Serantes eran de origen gallego y bien sabemos qué tan fuerte vínculo puede formarse entre dos personas aun siendo de carácter y condiciones tan distintas.

\footnotetext{
24 Thomas M. LEONARD, Fidel Castro: a Biography, Westport, 2004, 3.

${ }^{25}$ Birán era un pequeño asentamiento tipo finca en la antigua provincia de Oriente, a su vez fue el centro de las tierras de la familia Castro. Aquí se crio Fidel Castro, aunque ya muy joven, a los cinco años tuvo que dejar su hogar para comenzar sus estudios.

${ }^{26}$ Ignacio URÍA, op. cit., 66.
} 
Es interesante que Castro nunca en ninguna parte haya mencionado que conocía bien a Pérez Serantes. Según Thomas M. Leonard solo gracias a la intervención de Pérez Serantes fue aceptado Castro en el colegio jesuita de élite, en el Belén. ${ }^{27}$

La circular de Enrique Pérez Serantes publicada dos días después, refleja el mismo estado entusiasta y las esperanzas que compenetraron a las personas reunidas en el Parque Céspedes. El título de la circular es bastante significativo, Vida Nueva, que sugiere la finalización de una época y el comienzo de algo nuevo, lleno de esperanzas. El comienzo de la circular es la expresión de la sincera alegría por barrer con la dictadura Batista y por lograr la victoria. Coloca solo a un hombre en primer plano de los acontecimientos, a Fidel Castro, sobre quien se expresa con la mayor exaltación posible y lo describe como un hombre de dotes excepcionales. Aunque parece como si a la felicidad de la Iglesia le invadiera la duda y la inseguridad, al presentar el arzobispo los nueve puntos que forman el cuerpo principal de la circular a los nuevos dirigentes del país, Fidel Castro y Manuel Urrutia. En su escrito Pérez Serantes lleva simbólicamente más allá la escena acaecida en el Parque Céspedes, ya que allí, al lado del portón abierto de la Catedral del primado, bajo el amparo del visible altar, dio su juramento la nueva directiva del país, el presidente de Cuba, Manuel Urrutia Lleó. ${ }^{28} \mathrm{La}$ circular intentó asegurar para el gobierno este mismo amparo en forma de pantalla protectora intelectual, como consejo, como guía.

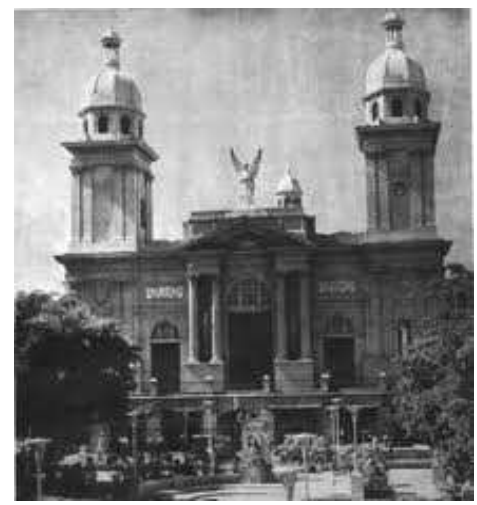

La Catedral en la Plaza Principal de Santiago de Cuba http://internos.occnet.cu/?q=node/374, fecha de consulta: 7 de agosto de 2014

\footnotetext{
27 Thomas M. LEONARD, op. cit., 3.

${ }^{28}$ Manuel Urrutia Lleó (1908-1981) abogado, político. Desempeñó el cargo de presidente del 3 de enero al 17 de julio de 1959. Su relación con Fidel Castro empeoró, por lo que renunció a su cargo, primero fue a la embajada venezolana y de ahí emigró a los Estados Unidos, falleció en Nueva York.
} 
¿Pero para qué esta prisa?, ¿por qué sentiría el arzobispo la obligación de tener que cumplir con esta tarea? Tras alcanzar la independencia, las cesuras políticas no trajeron consigo cambios favorables para la Iglesia Católica en toda la América Latina. Es harto conocido que las ideas liberales trasplantadas a las prácticas políticas significaron grandes pérdidas para ellos, en mi opinión son justamente estas experiencias adversas del pasado las que instan a Pérez Serantes a que exprese lo antes posible los requerimientos y expectativas de la Iglesia Católica con respecto al nuevo poder. Así, considero el Circular en parte como "arma" de autodefensa y en parte como manifestación para alcanzar una situación de ventaja que trató de aclarar los requerimientos en las cuestiones más elementales para la Iglesia. Implícitamente quiso reflexionar sobre lo dicho por Castro el primero de enero. El discurso de Castro fue extraordinariamente exaltador y a su vez apaciguador, prometiendo paz y tranquilidad, pero del futuro solo se expresó a nivel de insinuaciones. ${ }^{29}$ En el discurso encontramos ocultas alusiones difusas, en una parte habla de que la revolución hará cosas que anteriormente nunca se han hecho, unos minutos después expresó que ésta sería una verdadera revolución, pero no llegó a detallar nada más. Probablemente, esto es lo que habrá echado de menos el arzobispo, a su vez haciéndolo reflexionar sobre cómo debería interpretar este silencio, si debía tomarlo como un presagio. Justamente, esta falta es la que le insta a aclarar los fundamentos políticos y acorde a esto, toma una postura a favor de la creación de una verdadera democracia dirigida hacia la garantización, respeto de los derechos humanos fundamentales, hacia la justicia social. Aludiendo a nivel de mención a las enseñanzas de la Encíclica Inmortale Dei (1185) del Papa Leo XII, hace sentir que la definición de la relación ideal entre estado e iglesia la podemos encontrar en aquella circular apostólica.

En la Vida Nueva, entre los puntos a considerar podemos separar dos grandes grupos temáticos, por un lado, lo que representa el espíritu de la moral cristiana y por otro los requerimientos derivados de las enseñanzas sociales de la Iglesia. Podemos colocar en el primer grupo el énfasis en que los gobernantes deben dar ejemplo de religiosidad (puntos 1-2), porque es imposible que vivan sin Dios, al contrario, deben ser ellos quienes den ejemplo en la práctica de la fe alentando con ello a sus compatriotas. En esta temática podemos integrar la cuestión de la enseñanza (3. er punto) según la cual, en los colegios - háblese de cualquier tipo de formación - hay que vaciar las almas de los niños en el troquel cristiano: sublime forma de expresar el requerimiento de mantener la educación religiosa. Podemos enumerar aquí la santidad de la familia y la preocupación por los divorcios (4. ${ }^{\circ}$ punto), a este último, el circular lo atacó con bastante vehemencia pidiendo que el gobierno rompiera con las prácticas establecidas. Claramente alude a la ley promulgada por el Parlamento cubano, tras largas discusiones, el 29 de julio de 1918, en la que aseguró la posibilidad del divorcio,

${ }^{29}$ Discurso de Fidel Castro, Esta vez sí que es la Revolución, 1 de enero de 1959, Santiago de Cuba, Parque Céspedes, http://www.cubadebate.cu/opinion/2014/01/01/fidel-castro-el-1-de-enero-de1959-esta-vez-si-que-es-la-revolucion/\#.U77-6pR_uvc, fecha de consulta: 3 de abril de 2014.

Acta Hispanica 19: 27-37, 2014, ISSN: 1416-7263 |35 


\section{La Iglesia Católica cubana y el Estado en 1959 según la circular Vida Nueva}

siendo así el primer país en América Latina. ${ }^{30}$ También sorprendió esta noticia a los periodistas del Sol español, porque le dedicaron un breve reportaje al tema. ${ }^{31}$ Finalmente, en nombre de la moral cristiana, la circular prácticamente exige que limpien la sociedad de los focos de infección moral que ciertos periódicos y revistas, que entre sus trabajos incluyen hasta pornografía, vierten sobre la sociedad.

Entre los puntos de motivación social podemos agregar la intención de asegurar una vivienda digna, eliminando las pocilgas inmundas, llamar al campesino a que ame su tierra, gobernación en nombre de la justicia.

En su totalidad, considero que la Vida Nueva es el escrito que expresa la relación de la Iglesia Católica cubana con la revolución. Aunque es solo una circular de un prelado, el escrito tiene un alcance mucho más amplio, ya que proviene de la pluma del primado de Cuba, del dirigente de la comunidad católica del país. También sugiere lo mismo la temática de la circular, en realidad, trata de determinar o influir sobre la tendencia ideológica del nuevo gobierno, lo que de por sí va más allá de los marcos de su propio género. La considero también como una prueba de sugerir un programa, ya que el arzobispo trató con ello de adelantarse a los cambios políticos, toda la sociedad cubana tenía claro que la revolución podría conllevar transformaciones radicales en todos los ámbitos de la vida. Con esto, posiblemente quiso tranquilizar su conciencia, porque no pudo pensar en serio que el gobierno actuaría según los principios esbozados por él. Como si Enrique Pérez Seranto hubiera presentido en el estrado del Palacio Municipal que la relación armoniosa entre la Iglesia y el nuevo régimen sería efímera; había signos de que los "barbudos" 32 no eran amigos de los santos. El 5 de septiembre de 1958, unos días antes de las Fiestas y Procesión de la Virgen María, fueron ellos quienes profanaron la estatua de Nuestra Señora. Unos meses después, los miembros del Movimiento 26 de Julio trataron de remediar este error donando una medalla de oro a la estatua de Nuestra Señora, con la explicación de que sus actos en septiembre fueron motivados por la protesta contra la dictadura. ${ }^{33}$ A pesar de la torpe justificación, llama la atención que todavía consideraban necesarios los gestos para ganarse a los católicos, entre los que podemos incluir la donación de la medalla, o sea, no consideraban durante la segunda mitad de 1959 la ruptura con la iglesia como un objetivo. En enero de 1959, en el momento de la escritura de la circular se reconocían mutuamente. Fidel Castro en su discurso en La Habana unos días después, elogió a viva voz el comportamiento activo y auxiliador de los católicos mostrado durante la revolución. ${ }^{34}$ Él personalmente

\footnotetext{
30 Ángel ACEDO PENCO - Leonardo B. PÉREZ GALLARDO (eds.), El divorcio en el derecho Iberoamericano, Madrid, 2009, 213.

${ }^{31}$ El Sol informó sobre ello el 23 de agosto de 1918. En España todavía no era posible divorciarse.

${ }^{32}$ Los barbudos fue el nombre popular de los miembros del Movimiento 26 de Julio, ya que casi todos llevaban barba.

${ }_{33}^{3}$ Diario de la Marina, 6 de marzo de 1959, 8A.

34 “....es indudable que los católicos de la República prestaron su apoyo en forma extraordinaria con una actividad y valentía dignos del mayor encomio", in: Diario de la Marina, 7 de enero de 1959, 2A.
} 
tuvo mucho que agradecerles, principalmente a Enrique Pérez Serantes, quien intervino personalmente a favor de Fidel Castro tras el ataque al cuartel de la Moncada por parte de los integrantes del Movimiento del 26 de Julio, y según algunos historiadores y coetáneos él fue quien le salvó la vida. ${ }^{35}$ Ciertamente allanaban la relación EstadoIglesia las colectas de dinero organizadas por las comunidades católicas a favor de las personas que mayores penurias sufrían, para los más necesitados durante la guerra civil. Con esto no quiero sugerir, que estas actividades eclesiales fueron motivadas por la intención de mejorar las relaciones, sino más bien, fueron motivadas por la sensibilidad mostrada hacia los problemas sociales. ${ }^{36}$ Los ofrecimientos de los creyentes católicos respaldan más bien que realmente apoyaban la etapa temprana de la revolución, su empatía también se mostró con sus acciones y con sus sacrificios financieros.

Tomando todo en cuenta, la Vida Nueva muestra claramente el apoyo ofrecido a la lucha del Ejército Rebelde por parte de la Iglesia y los feligreses, quienes vieron a Fidel Castro como líder y al personaje incuestionablemente más sobresaliente, sobre quien se expresaron con el mayor reconocimiento. Castro fue extraordinariamente popular, su popularidad en la época inicial solo siguió incrementándose. Su persona se podía apoyar, no solamente para los estratos sociales inferiores, sino también para la clase media cubana, porque formalmente era aceptable para las convenciones, provenía de una familia terrateniente de la provincia, estudió en el mejor colegio privado jesuita, cursó derecho en la Universidad de La Habana, llegó a ser abogado y se casó con una mujer de una familia influyente. Ya es otra historia que con su política qué tanto cumplió con las convenciones, qué tanto llegó a sorprender a sus compatriotas y al mundo entero.

\footnotetext{
${ }^{35}$ Ignacio URÍA, op. cit., 139-161.

${ }^{36}$ Diario de la Marina, 6 de marzo de 1959, 8A.
} 